\title{
The Effect of Energy Consumption on Output: A Panel Data Study of Manufacturing Industries in Egypt
}

\author{
By Iman Al-Ayouty ${ }^{1}$
}

\begin{abstract}
Subsidizing electricity and non-electrical energy products has affected manufacturing output in Egypt, especially given the structure of Egypt's manufacturing sector which leans heavily towards capital- and energy-intensive products. This effect is captured in a production function estimated for the twenty industries making up Egypt's manufacturing sector over the period 2002-2016. With homogeneous parameters, the estimated output elasticity of energy is 0.28 . With panel member parameter heterogeneity, the output elasticity of energy is positive and statistically significant in ten manufacturing industries. Negative and statistically significant elasticity is however found in refined petroleum products, fabricated metal products, and electrical machinery and equipment. This indicates suboptimal energy use. Elasticity is also negative, though statistically insignificant, in: textiles, basic metals, and "other manufacturing". Except for "other manufacturing", industries of negative elasticity are all energy-intensive. Moreover, refined petroleum, fabricated metals and basic metals are pollutionintensive. A priority policy measure is to remove subsidies from energy inefficient and polluting industries as opposed to mere 'across-the-board' removal.
\end{abstract}

Keywords: energy consumption; manufacturing industries; energy- and pollution intensive; Egypt

\section{Introduction}

Egypt has a history of subsidizing energy products (both in the electricity and non-electrical forms) such that energy prices were almost constant from 1991-2012. Various energy products were priced at mere fractions of their economic costs ${ }^{1}$, and energy subsidies alone constituted 20 percent of total government expenditure in 2012-2013. Against this backdrop of heavy burden on the budget, the Egyptian government undertook aggressive adjustments to energy prices starting that year 2013 and expected to be complete by $2020^{2}$. But the cost to the budget was not the sole cost. Energy subsidies are expected to have also come at a cost to efficiency. Energy consumption of most industrial processes and equipment in Egypt was estimated to be 20 percent (or more) above best international practices (World Bank 2010). The efficiency cost cannot, therefore, be overlooked, especially in those industries which are energy-intensive and which have relied on heavily-subsidized energy.

Applied research relevant to the relation of energy and output in Egypt is indeed scarce,

\footnotetext{
${ }^{1}$ Electricity for the industrial, residential and commercial sectors was estimated to be priced at 26-44 percent, 25 percent, and 26-44 percent of their respective economic costs in 2012 (Castel (2012)).

2 Under the COVID-19 pandemic, the Egyptian government has recently announced that subsidy removal phasing out period will be extended beyond 2020 till 2023.
}

| ${ }^{1}$ Assistant Professor of Economics, Faculty of Business and International Trade, Misr International University, Cairo, Egypt 
and is mostly of a technical engineering nature (see for example, Kamel (2017)). Thus, the main motivation of the present study is to answer the question whether heavilysubsidized' energy has contributed positively or negatively to output through investigating the long-term relation of energy consumption and output. To do so, a production function for a panel of twenty industries (making up Egypt's manufacturing sector) is estimated for the period 2002-2016. Selection of the period of study was determined by two factors. The first is that real manufacturing output has achieved an average annual rate of growth of $5 \%$ over the respective period (source: calculated from Annual Bulletin of Industrial Production Statistics issued by Egypt's Central Agency for Public Mobilization and Statistics (CAPMAS)). The second selection factor is that Egypt began its subsidy removal measures in fiscal year 2014/2015. The period 2002-2016 is therefore one during which energy was heavily subsidized, making it possible to capture the effect of energy on output with subsidies in place.

As a first step, the production function estimation is performed assuming parameter homogeneity for panel members. Subsequently, it is performed assuming parameter heterogeneity, thereby obtaining estimates of energy-output effect for each manufacturing industry. To the best of the author's knowledge, no such estimation has been previously attempted, and the present study thereby aims to fill a gap in literature relevant to Egypt. This could also be of significance to other countries with similar industrial structure, where industries are also heavily energy-reliant and where energy subsidies were in place.

The rest of the study is organized as follows: section 2 reviews the literature - theoretically and empirically; section 3 gives the data and variable description, and highlights the methodology; section 4 gives the estimation results, section 4 outlines the results, section 5 gives a discussion of results and draws key policy implications.

\section{Literature Review}

Studies of biophysical economics focused on the energy-output relation and have partly addressed questions of energy as a source of economic growth. A principal finding was that of a strong correlation between energy use and gross output (in USA) (for example, Cleveland et al. (1984)). However, many of these studies assume a priori causal relationships between energy use and the production of output (Stern, 1993:138). Energy is itself the primary factor of production, while labour and capital are intermediate factors that require energy and materials in order for them to produce and be maintained.

Contrary to this, neoclassical economists held that energy has a minor role in output production, and that capital, labour and land are the primary factors of production. In this regard, studies have mostly focused on the effect of energy use or prices on output. Some studies (e.g., Burgess (1984), Denison (1979), Brendt (1980)) were criticized for relying on a priori assumptions of energy use (taken from empirical estimates of energy parameters), other studies for deriving energy use data rather than using actual energy consumption data (e.g., Rasche and Tatom (1977)).

An important contribution of Schurr (1982) was to establish the existence of an inverse relation between the U.S. economy's energy consumption to GNP ratio (energy intensity) and total factor productivity (TFP). While energy intensity fell over the 1920s and early 1960s, TFP rose. That relation existed in the U.S. industrial sector, too. The author 
explained that energy intensity fell due to the abundance of low-cost energy, as well as flexibility of using electricity and fluid forms of energy compared to solid energy forms. This led to energy being utilized in new processes which, in turn, sped up technical advances and raised TFP.

Jorgenson (1984) used econometric price functions for individual U.S. industrial sectors, where each price function gave the price of output of the sector as a function of the prices of capital, labour, material inputs, electricity and non-electrical energy, and time trend to represent the level of technology in the sector. The model is then expressed in an alternative form whereby "shares of each of the aforementioned inputs in output" is expressed as a function of the price each inputs and of time (i.e., level of technology). The bias of technical change appears as the coefficient of time with respect to each of the value shares of the inputs. If productivity growth is biased towards electricity, for example, the electricity coefficient is positive. The author finds productivity growth (i.e., technical change) to be biased either towards an increased use of electricity or an increased use of non-electrical energy. Jorgenson's findings were in line with Schurr (1982) whereby a reduction in the costs of electricity and non-electrical energy led to productivity growth. Other works, for example Cleveland (1995) and Felloni et al. (1999), were oriented towards estimating production functions so as to examine how economic sectors- with much emphasis on agriculture- were increasingly dependent on low-priced energy (electricity, fossil fuels and natural gas), and how this was also coupled with increased capital intensity for sectors, and the ensuing effect on output and TFP.

Regarding impacts of energy consumption and growth on total factor productivity are Karkacier et al. (2005) and Moghaddasi and Pour (2016), with application to agriculture in Turkey and Iran, respectively. For the period 1970-2003, Karkacier et al. (2005) estimate a productivity response model where the index of agricultural productivity is regressed on the energy consumption of the agricultural sector and the gross additions to fixed assets of the sector. Results indicated the existence of a strong relationship between energy use and agricultural productivity. Worthy of note is that between the 1970's and 2000's, energy use was increasing in all of Turkey's economic sectors, in general, and in agriculture, in particular. Moghaddasi and Pour (2016) addressed the long run relation of energy consumption and growth in total factor productivity via production function estimation for Iranian agriculture for the period 1974-2012. Their methodology used cointegration analysis, as the dependent variable (agricultural value added), and the independent variables (capital stock, labour and energy consumption) were all non-stationary. The authors conclude that heavily subsidized cheap energy has encouraged the use of energy at levels far more than the optimum, and has led to a fall in TFP growth.

\section{Methodology}

Following mainstream literature and applied research, and method used in Moghaddasi and Pour (2016), a production function for Egypt's manufacturing sector (comprised of 20 manufacturing industries) is estimated for the period 2002-2016. The choice of the period 2002-2016 is based on the fact that this period had the highest level of industrial growth and energy subsidies for the manufacturing industry in Egypt. 


\subsection{Choice of Variables}

Output is measured as the value of output in current market prices. Inputs are labour, capital and energy. Labour is measured as the total number of employees in the industry by year. Capital is measured as the value of end of year stock of fixed assets. The expected signs of the coefficients for labour and capital are positive, where labour and capital increases are expected to reflect positively on output. This is in keeping with numerous production function estimations, at aggregate and at micro levels. Energy is measured as expenditure on electricity and non-electrical energy by the industry by year. The expected sign of energy may be either positive or negative (if increased energy use is associated with a decline in output).

Nominal values of output, capital and energy are deflated using the producer price index of the respective industry by year. All variables are measured in their natural logarithms.

\subsection{Data sources}

Data for output and inputs are from the "Annual Bulletin of Industrial Production Statistics" issued by CAPMAS (issues of 2002-2016). Data for the producer price index by industry are from the "Annual Bulletin of Producer Price Index" issued by CAPMAS (issues of 2002-2016).

\subsection{Method}

Appendix A summarizes the tests performed to estimate the production function in the appropriate specification. As a first step, we test for the stationarity of the variables and subsequently a Cobb-Douglas production function is estimated assuming parameter homogeneity for panel members (i.e., manufacturing industries):

$\mathrm{Y}_{i t}=\mathrm{AL}_{i t} \beta_{1} \mathrm{~K}_{i t} \beta_{\mathrm{k}} \mathrm{E}_{i t}{ }_{\mathrm{e}} e^{u i t}$,

$i=1, \ldots, 20 ; t=1, . ., 15$

$\mathrm{A}=$ technology/technological change parameter (i.e., TFP)

$\mathrm{Y}_{i}=$ value of output of industry $i$ at point $t$,

$\mathrm{L}_{i F} \rightleftharpoons$ total labour employed in industry $i$ at point $t$;

$\mathrm{K}_{i}=$ value of capital stock of industry $i$ at point $t$,

$\mathrm{E}_{i t}=$ value of electricity and non-electrical energy used by industry $i$ at point $t$,

$\mathrm{u}_{i t}=$ error term assumed to be i.i.d $\left.\sim \mathrm{N}\left(0, \sigma^{2}\right)\right)$ and not correlated with explanatory variables. Taking the natural logarithm of both sides renders:

$\ln \mathrm{Y}_{i t}=\alpha+\beta_{1} \ln \mathrm{L}_{i t}+\beta_{\mathrm{k}} \ln \mathrm{K}_{i t}+\beta_{\mathrm{e}} \ln \mathrm{E}_{i t}+\mathrm{u}_{i t}$

Where, $a=\ln \mathrm{A}$, and $\beta_{l}, \beta_{k}$ and $\beta_{e}$ give the elasticity of output with respect to labour, capital and energy, respectively.

The appropriate specification for the model may be of pooled ordinary least square in which there are no idiosyncratic effects for either the panel member or time, and as such " $\alpha$ " does not vary for any of the panel members. Alternatively, specification may be of fixed effects such that " $\alpha$ " may reflect the unobservable fixed effects which vary with respect to the panel member only, with respect to time only, or with respect to both the panel member and time. Specification may also of random effects where " $u_{i t}$ " capture unobservable effects which vary with respect to panel member, time, or both.

Testing for the appropriate specification of the model is first performed for pooled least 
squares using F-ratio test:

$$
F_{(N-1)(N T-N-k)}=\frac{\left(R_{F E}^{2}-R_{P O O L E D}^{2}\right) /(N-1)}{\left(1-R_{F E}^{2}\right) /(N T-N-k)}
$$

Where $\mathrm{N}$ denotes the number of panel members, $\mathrm{T}$ is the number of years, $\mathrm{k}$ is the number of estimated parameters, $\mathrm{R}^{2}$ is the regression sum of squares of pooled and fixed effects estimations, respectively. Subsequently for the fixed versus random effects specification using the Hausman test (also testing for the existence of panel member and/or time effects) using the Wald statistic (where $\mathrm{W}$ is distributed as $\left.\chi^{2}(\mathrm{k}-1)\right)$.

$W=\left(\beta_{\text {FixedEffects }}-\beta_{\text {RandomEffects }}\right)^{\prime} \psi^{-1}\left(\beta_{\text {FixedEffects }}-\beta_{\text {RandomEffects }}\right)$

Where $\beta$ is the vector of estimated parameters using the fixed and random effects, respectively, and $\psi$ is of the vector of $\left(\operatorname{Var}\left(\beta_{\text {FixedEffects }}\right)-\operatorname{Var}\left(\beta_{\text {RandomEffects }}\right)\right.$.

Prior to carrying out the second step of estimation, the test for parameter heterogeneity for panel members is carried out. The test verifies whether indeed parameter heterogeneity is an appropriate specification. It relies on the restriction-test statistic, where the homogeneous slope model is the restricted model. The restricted-test statistic is $\mathrm{F}=$ $\left[\left(\left(\mathrm{ESS}_{\mathrm{R}}-\mathrm{ESS}_{\mathrm{UR}}\right) /(\mathrm{N}-1)\right) /\left(\mathrm{ESS}_{\mathrm{UR}} /(\mathrm{N}(\mathrm{T}-\mathrm{K}-1))\right]\right.$, and under $\mathrm{H}_{0}$, this $\mathrm{F}$ statistic is distributed

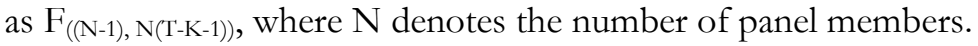

Given this specification, the production function takes the form:

$\ln Y_{i t}=a+\beta_{l i} \ln L_{i t}+\beta_{k i} \ln K_{i t}+\beta_{e i} \ln E_{i t}+u_{i t}$

Where, $\beta_{l i}, \beta_{k i}, \beta_{e i}$ give the elasticity of output with respect to labour, capital and energy, respectively, varying for each panel member $i$.

\section{Results}

Since time series data are used, testing for the stationarity of the variables was performed using the augmented Dickey Fuller and the Philips-Perron unit root tests. Test results are given in Table 1.

Table 1. Results of unit root tests.

\begin{tabular}{|c|c|c|}
\hline Variable (in level) & Augmented Dickey Fuller & Phillips-Perron \\
\hline LnY & $81.212^{* * *}$ & $116.061^{* * *}$ \\
\hline LnL & $116.662^{* * *}$ & $138.374^{* * *}$ \\
\hline LnK & $71.542^{* * *}$ & $68.427^{* * *}$ \\
\hline LnE & $102.599^{* * *}$ & $145.560^{* * *}$ \\
\hline
\end{tabular}

$1 * * *$ are significant at $\% 1$ level of significance

Source: Author's Computations

Given that all variables established stationarity in their levels using both the augmented Dickey Fuller and the Phillips-Perron tests, it was then appropriate to use these variables as levels for production function estimation (initially assuming parameter homogeneity for panel members). However, the appropriate specification for estimation (pooled least squares, fixed versus random effects specification) needed to be determined. Specification test results indicated the inequality of the $\alpha$ 's, making the pooled least squares specification inappropriate. Test results are given in'Table 2. 
Table 2. Results of pooled specification test

\begin{tabular}{|c|c|c|}
\hline $\mathrm{F}(19,257), \alpha=0.01$ & 1.90 & $\mathrm{H}_{\mathrm{o}:} \alpha_{1}=\alpha_{2}=\ldots=\alpha_{\mathrm{N}}$ \\
$\mathrm{H}_{1:} \alpha_{1} \neq \alpha_{2} \neq \ldots \neq \alpha_{\mathrm{N}}$ \\
F statistic & \multirow{2}{*}{$18.4429^{* * *}$} & Conclusion: reject $\mathrm{H}_{0}$ and do not reject $\mathrm{H}_{1}$. \\
\hline
\end{tabular}

$1 * * *$ are significant at $\% 1$ level of significance

Source: Author's Computations

Results of further testing for fixed versus random effects specification using the Hausman test ruled in favour of the fixed effects specification. Test results are given in Table 3.

Table 3. Results of fixed versus random effects specification test

\begin{tabular}{|l|l|l|}
\hline $\begin{array}{l}\mathrm{X}^{2}(\mathrm{k}-1), \\
\alpha=0.01\end{array}$ & 9.21 & $\begin{array}{l}\mathrm{H}_{\circ}: \mathrm{E}\left(\alpha_{\mathrm{i}} \mid \mathrm{X}_{\mathrm{i}}\right)=0 \text { (difference in coefficients is not systematic, hence } \\
\text { random effects) }\end{array}$ \\
\hline W statistic & $35.0363^{* * * *}$ & $\begin{array}{l}\mathrm{H}_{1}: \mathrm{E}\left(\alpha_{\mathrm{i}} \mid \mathrm{X}_{\mathrm{i}} \neq 0 \text { (difference in coefficients is systematic, hence fixed }\right. \\
\text { effects) } \\
\text { Conclusion: reject } \mathrm{H}_{0} \text { and do not reject } \mathrm{H}_{1} \quad \therefore \text { The appropriate } \\
\text { specification is fixed effects. }\end{array}$ \\
\hline
\end{tabular}

$1 * * *$ are significant at $1 \%$ level of significance

${ }^{2}$ With insufficient observations, it was not possible to proceed with the $\mathrm{F}$ test used to test for whether the fixed effects are of the time period type only, of panel member (cross section) type only, or of both time period and cross section type. Our conclusion was therefore to use the specification of cross section type only

Source: Author's Computations

The results of the first step of estimation of the production function assuming constant parameters for panel members with fixed effects specification are, therefore, given in Table 4.

Table 4. Results of production function estimation with homogeneous parameters for panel members.

\begin{tabular}{|c|c|c|c|}
\hline $\begin{array}{l}\text { Dependent Variable } \\
\text { Method: Pooled Lea } \\
\text { Sample: } 20022016 \\
\text { Included observation } \\
\text { Cross-sections inclu } \\
\text { Total pool (balanced }\end{array}$ & $\begin{array}{l}0 \\
\text { ervations: } 300\end{array}$ & & \\
\hline Variables & Coefficient & Std. Error & Prob. \\
\hline Constant & 1.498693 & 0.538890 & $0.0058^{* * *}$ \\
\hline LRCAPITAL & 0.827078 & 0.085819 & $0.0000^{* * *}$ \\
\hline LLABOUR & 0.138411 & 0.059651 & $0.0210^{* *}$ \\
\hline LRENERGY & 0.287164 & 0.056573 & $0.0000^{* * *}$ \\
\hline \multicolumn{4}{|c|}{ Cross-section fixed (dummy variables) } \\
\hline R-squared & 0.950223 & & \\
\hline Adjusted R-squared & 0.946269 & & \\
\hline S.E. of regression & 0.411004 & & \\
\hline Sum squared resid & 46.79208 & & \\
\hline F-statistic & 240.35340 & & \\
\hline
\end{tabular}


Prob(F-statistic) $\quad 0.00000$

${ }^{1}$ cross section fixed effects coefficients not shown

$2 * * *$ significant at $1 \%$ level of significance, ${ }^{* *}$ significant at $5 \%$ level of significance

Source: author's results

As indicated in Table 4 all capital and energy are statistically significant at $1 \%$ level, though labour is significant at the $5 \%$ level. A one percent change in labour, capital and energy leads to $0.14,0.83$ and 0.28 percent changes in manufacturing output, respectively. Evidently, capital and energy show greater impact on output compared to labour. This may reflect the strong leaning of the structure of the manufacturing sector toward capitaland energy-intensive industries which, on average, account for 72 percent of manufacturing output, on average for the period 2002-2016 (source: calculated from CAPMAS “Annual Bulletin of Industrial Production Statistics”, 2002-2016).

As per results given in Table 5, the appropriate model specification is found to be the heterogeneous parameters for panel members:

Table 5. Results of heterogeneous parameters for panel members test

\begin{tabular}{|c|c|c|}
\hline $\begin{array}{l}F(14,165) \\
\alpha=0.01\end{array}$ & 2.06 & $\begin{array}{l}\mathrm{H}_{0}: \beta_{11}=\beta_{12}=\ldots .=\beta_{\mathrm{li}} ; \beta_{\mathrm{k} 1}=\beta_{\mathrm{k} 2}=\ldots . \ldots \beta_{\mathrm{ki}} ; \beta_{\mathrm{e} 1}=\beta_{\mathrm{e} 2}=\ldots . . \\
\mathrm{H}_{1}: \beta_{11} \neq \beta_{12} \neq \ldots \neq \beta_{\mathrm{ei}} .\end{array}$ \\
\hline $\begin{array}{l}\text { F statistic } \\
\text { (restriction test) }\end{array}$ & 7.18 & $\begin{array}{l}\text { Conclusion: reject } \mathrm{H}_{0} \text { and do not reject } \mathrm{H}_{1}, \therefore \text { The appropriate } \\
\text { specification is heterogeneous parameters for panel members. }\end{array}$ \\
\hline
\end{tabular}

$1 * * *$ significant at $1 \%$ level of significance

Source: Author's Computations

The model's estimation results are given

Table 6.

Table 6. Results of estimation with heterogeneous parameters for panel members

\begin{tabular}{|c|c|c|c|}
\hline \multicolumn{4}{|c|}{$\begin{array}{l}\text { Dependent Variable: LROutput } \\
\text { Method: Pooled EGLS (Cross-section weights) } \\
\text { Sample: } 20022016 \\
\text { Included observations: } 15 \\
\text { Cross-sections included: } 20 \\
\text { Total pool (balanced) observations: } 300 \\
\text { Linear estimation after one-step weighting matrix }\end{array}$} \\
\hline Variables & Coefficient & Std. Error & Prob \\
\hline Constant & 3.117627 & 1.418104 & $0.0290^{* *}$ \\
\hline LRCapital_FB & 2.019488 & 0.795239 & $0.0118^{* *}$ \\
\hline LRCapital_TB & 2.010338 & 1.103626 & $0.0699 *$ \\
\hline LRCapital_TEX & 0.204930 & 0.077924 & $0.0091 * * *$ \\
\hline LRCapital_APPRL & 0.342187 & 0.271277 & 0.2085 \\
\hline LRCapital_LTH & 0.918156 & 0.287808 & $0.0016^{* * *}$ \\
\hline LRCapital_WD & 0.273704 & 0.229226 & 0.2337 \\
\hline LRCapital_PAP & 0.889707 & 0.352087 & $0.0122 * *$ \\
\hline LRCapital_PRNT & 1.791630 & 1.043917 & $0.0875^{*}$ \\
\hline LRCapital_RPET & 1.729398 & 0.449554 & $0.0002^{* * *}$ \\
\hline LRCapital_CHEM & 1.512925 & 0.543807 & $0.0059 * * *$ \\
\hline
\end{tabular}




\begin{tabular}{|c|c|c|c|}
\hline LRCapital_RUB & 1.847534 & 0.675777 & $0.0068^{* * *}$ \\
\hline LRCapital_NONMET & -0.063934 & 0.635932 & 0.9200 \\
\hline LRCapital_BMETS & 0.267150 & 0.580000 & 0.6455 \\
\hline LRCapital_METS & 0.507485 & 0.433179 & 0.2427 \\
\hline LRCapital_NONELECT & 0.103129 & 0.511850 & 0.8405 \\
\hline LRCapital_ELECT & 1.309401 & 0.297054 & $0.0000^{* * *}$ \\
\hline LRCapital_VEH & 0.365361 & 0.950998 & 0.7012 \\
\hline LRCapital_OTRANSP & -1.315276 & 0.655952 & $0.0462 * *$ \\
\hline LRCapital_FURN & 0.703844 & 0.312782 & $0.0254^{* *}$ \\
\hline LRCapital_OMFG & 1.483740 & 0.703518 & $0.0361 * *$ \\
\hline LLabour_FB & 0.051035 & 0.087637 & 0.5609 \\
\hline LLabour_TB & 0.066334 & 0.293773 & 0.8216 \\
\hline LLabour_TEX & 0.091691 & 0.065058 & 0.1601 \\
\hline LLabour_APPRL & 0.009577 & 0.136252 & 0.9440 \\
\hline LLabour_LTH & 0.196037 & 0.357072 & 0.5836 \\
\hline LLabour_WD & 0.179040 & 0.096596 & $0.0652 *$ \\
\hline LLabour_PAP & 0.112681 & 0.082400 & 0.1729 \\
\hline LLabour_PRNT & -0.558632 & 0.387126 & 0.1504 \\
\hline LLabour_RPET & -0.024704 & 0.102141 & 0.8091 \\
\hline LLabour_CHEM & -0.484039 & 0.350817 & 0.1691 \\
\hline LLabour_RUB & 0.196516 & 0.386100 & 0.6113 \\
\hline LLabour_NONMET & 0.111570 & 0.311053 & 0.7202 \\
\hline LLabour_BMETS & -0.036750 & 0.052997 & 0.4888 \\
\hline LLabour_METS & -0.217063 & 0.271947 & 0.4256 \\
\hline LLabour_NONELECT & -0.085994 & 0.328549 & 0.7938 \\
\hline LLabour_ELECT & 0.951229 & 0.333481 & $0.0048^{* * *}$ \\
\hline LLabour_VEH & 0.655649 & 0.451609 & 0.1480 \\
\hline LLabour_OTRANSP & 0.703398 & 0.200360 & $0.0005^{* * *}$ \\
\hline LLabour_FURN & 0.354265 & 0.272790 & 0.1954 \\
\hline LLabour_OMFG & -0.215612 & 0.810128 & 0.7904 \\
\hline LREnergy_FB & 0.399210 & 0.194439 & $0.0412^{* *}$ \\
\hline LREnergy_TB & 0.359572 & 0.199480 & $0.0728 *$ \\
\hline LREnergy_TEX & -0.043645 & 0.075741 & 0.5650 \\
\hline LREnergy_APPRL & 0.518428 & 0.088314 & $0.0000^{* * *}$ \\
\hline LREnergy_LTH & 0.197441 & 0.360550 & 0.5845 \\
\hline LREnergy_WD & 0.064489 & 0.073743 & 0.3828 \\
\hline LREnergy_PAP & 0.456179 & 0.079284 & $0.0000^{* * *}$ \\
\hline LREnergy_PRNT & 0.234252 & 0.255766 & 0.3607 \\
\hline LREnergy_RPET & -0.403986 & 0.200419 & $0.0450 * *$ \\
\hline LREnergy_CHEM & 0.475959 & 0.112268 & $0.0000 * * *$ \\
\hline LREnergy_RUB & 0.464642 & 0.135402 & $0.0007 * * *$ \\
\hline LREnergy_NONMET & 0.376328 & 0.171760 & $0.0295^{* *}$ \\
\hline LREnergy_BMETS & -0.157260 & 0.104911 & 0.1353 \\
\hline LREnergy_METS & -0.345007 & 0.209072 & $0.1003^{*}$ \\
\hline LREnergy_NONELECT & 0.511281 & 0.210955 & $0.0162 * *$ \\
\hline LREnergy_ELECT & -0.654650 & 0.349072 & $0.0621 * *$ \\
\hline LREnergy_VEH & 0.474094 & 0.287300 & $0.1003^{*}$ \\
\hline LREnergy_OTRANSP & 0.102852 & 0.343889 & 0.7652 \\
\hline LREnergy_FURN & 0.626093 & 0.134602 & $0.0000^{* * *}$ \\
\hline
\end{tabular}




\begin{tabular}{|l|c|c|c|}
\hline LREnergy_OMFG & -0.14631 & 0.635753 & 0.8182 \\
\hline Cross-section fixed (dummy variables) & & \\
R-squared & 0.991518 & & \\
Adjusted R-squared & 0.988473 & & \\
S.E. of regression $\quad 0.369297$ & & \\
Sum squared resid $\quad 30.00371$ & & \\
F-statistic & 325.5469 & & \\
Prob(F-statistic) & 0.000000 & & \\
\hline
\end{tabular}

1 Acronyms with ISIC rev.4 2-digit classification number: FB (food products and beverages, 10\&11); TB (tobacco products, 12); TEX (textile, 13); APPRL (wearing apparel, 14); LTH (leather and related products, 15); WD (wood and products of wood and cork, 16); PAP (paper and paper products, 17); PRNT (printing and reproduction of recorded media, 18); RPET (coke and refined petroleum products, 19); CHEM (chemicals and chemical products, 20 and pharmaceutical, medicinal chemicals and botanical products, 21); RUB (rubber and plastic products, 22); NONMET (other non-metallic mineral products, 23); BMETs (basic metals, 24); METS (fabricated metal except machinery, 25); NONELECT (non-electrical machinery and equipment, 28); ELECT (computer, electronic and electrical equipment, 26 and27); VEH (vehicles, trailers and semi-trailers, 29); OTRANSP (other transport equipment, 30); FURN (furniture, 31); OMFG (other manufacturing, 32)

${ }^{2}$ Cross section fixed effects coefficients not shown

$3 * * *$ are significant at $1 \%$ level of significance, ** significant at $5 \%$ level of significance, * significant at $10 \%$ level of significance.

Source: Author's Computations

The elasticity of output with respect to energy is positive and statistically significant for the following industries: food and beverages, tobacco, apparel, paper, chemicals (including pharmaceuticals), rubber, non-metallic mineral products, non-electrical machinery and equipment, vehicles, and furniture.

Refined petroleum product, fabricated metal products except machinery, and electrical machinery and equipment show a negative and statistically significant elasticity of output with respect to energy. This indicates a suboptimal use of energy, which is also evident for textiles, basic metals (ferrous and non-ferrous) and other manufacturing industries (although estimated parameters are not statistically significant). The above result is in line with Moghaddasi and Pour (2016) with a negative elasticity of TFP with respect to energy use in Iranian agriculture sector in which energy was heavily subsidized.

Refined petroleum products, fabricated metal products except machinery, electrical machinery, textiles, and basic metals are industries which are both capital- and energyintensive industries. With negative output elasticity with respect to energy, these industries' energy intensity is therefore coupled with a sub-optimal energy use. Moreover, three of these industries (namely, refined petroleum product, fabricated metal products except machinery, and basic metals) are pollution-intensive industries ${ }^{3}$, making them both energy-

\footnotetext{
${ }^{3}$ For identification of pollution-intensive (i.e., dirty) industries, see Mani and Wheeler (1998). The authors' identification is based on two criteria: (1) sectors/industries incurring high levels of abatement expenditure per unit of output; (2) sectors' actual emissions intensity per unit of output. Based on the two criteria, industries ranked in order of pollution intensity are: ferrous and non-ferrous basic metals; industrial chemicals, refined petroleum products, non-metallic mineral products, paper and pulp, rubber, leather, and fabricated metal
} 
intensive, and environmentally hazardous industries.

For the environmental implications of the above-mentioned industries, we refer to Figure 2 which gives a map of $\mathrm{CO}_{2}$ emissions across the governorates of Egypt in 2016. The map shows heavy clustering of $\mathrm{CO}_{2}$ emissions in the region of Greater Cairo (made up of the governorates of Cairo, Kalyoubia, and Giza), and high emissions also in Alexandria, Suez, Sharkia, and in the governorates of the southern regions (Asyout and Qena). In 2016, the share of each governorate's output generated by refined petroleum product, fabricated metal products except machinery, and basic metals in the output of these three industries nation-wide is: Greater Cairo's 25\%; Alexandria is 43\%; Asyout and Qena 11\%; Suez 8\%; Sharkia 6\% (source: Author's Computations). The high $\mathrm{CO}_{2}$ emissions shown in Figure 1 are thus associated with these governorate's respective share in the nation-wide output of refined petroleum product, fabricated metal products except machinery, and basic metals industries.
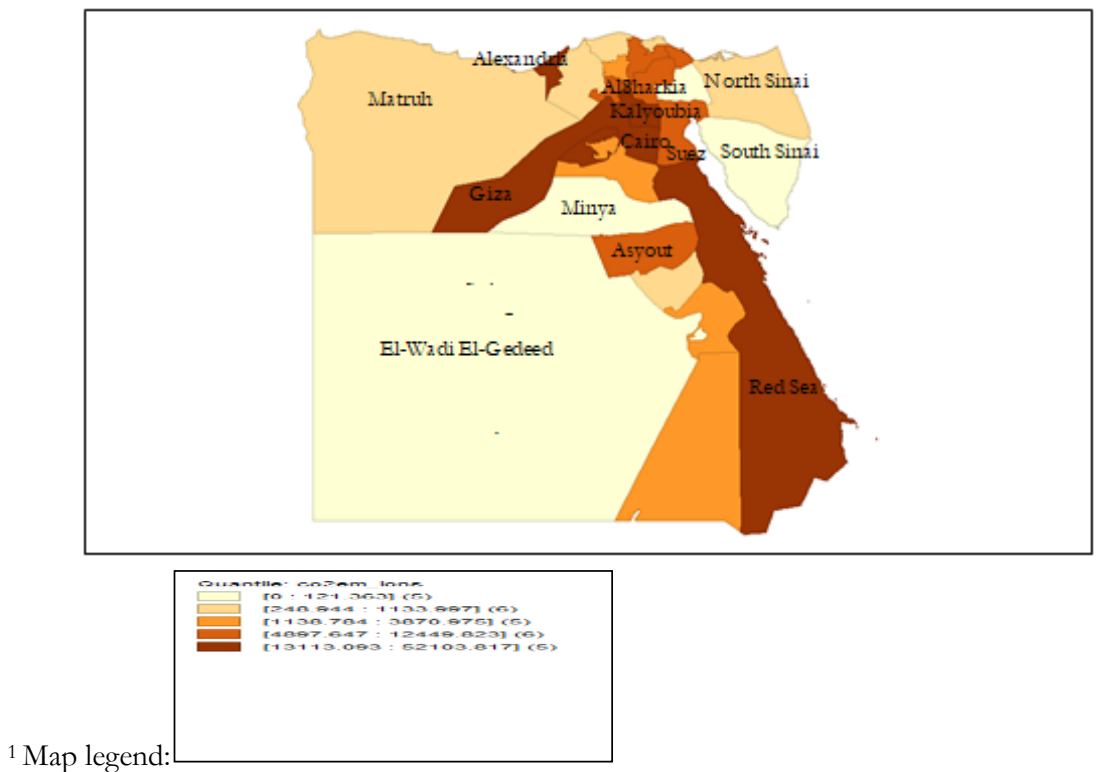

2 Notes: $\mathrm{CO}_{2}$ emissions data are not available at the governorate-level in Egypt. The share of each governorate's output of polluting energy-intensive industries in nation-wide polluting energy-intensive industries multiplied by the $\mathrm{CO}_{2}$ emissions from fossil fuels combustion (based on World Bank 'World Development Indicators' data) was used a proxy for $\mathrm{CO}_{2}$ emissions in the respective governorate

Figure 1. Map of $\mathrm{CO}_{2}$ emissions in Egypt's governorates, 2016

Source: reproduced from Al-Ayouty, Hassaballa and El Hini (2019)

\section{Discussion}

Results indicate that energy contributes positively to output in the following manufacturing industries (with a positive and statistically significant elasticity of output with respect to energy): food and beverages; tobacco; apparel; paper; chemicals (including

products except machinery. In contrast, clean industries are: textiles; nonelectrical machinery, electrical machinery, transport equipment (Mani and Wheeler, 1998:220-221). 
pharmaceuticals); rubber; nonmetallic mineral products; non-electrical machinery and equipment; vehicles; furniture. Studying the causes behind this, and thus replicating in other industries is advisable. The results also indicate that industries like refined petroleum product, fabricated metal products except machinery, and electrical machinery and equipment show a negative elasticity of output with respect to energy pointing to a suboptimal use of energy. Such suboptimal energy use is coupled with pollution intensity in refined petroleum product, fabricated metal products except machinery. Thus, promoting the efficient use of energy in these industries is a must.

As a first step, it is essential to make information about the efficient use of energy available to firms. Second, it is essential to support the availability of efficient techniques of production at a low cost. To complement this support, a third step would be to incentivise an active engagement of firms in energy efficiency. Incentives could come in the form of giving low cost loans conditional on energy-efficient investments, as well as giving tax breaks specifically to these industries to encourage their efficient energy use. As a fourth step, it is very important to give correct advice to firms when they switch to the use of energy-efficient techniques. Hence, relying on experts in the field of energy efficiency is much needed. Fifth, to promote research and development on the most efficient use of energy, with emphasis on efficiency which is associated with cost effectiveness and reduction of negative environmental effects. Sixth, set stricter energy efficiency standards for machines and equipment used in production. This requires imposing penalties on violating firms, while rewarding complying ones. Seventh, revise the removal of subsidy programme to decide on whether it should be done across the board for all types of industries, since not all industries are energy efficient. In this case, removal of subsidy from inefficient energy users may be given priority, as subsidy may be fuelling more inefficient use of energy. Ninth, encourage the use of renewable sources of energy, which would doubly tackle the negative environmental effects, especially of the pollution intense industries. Finally, rank the efficient use of energy as a top priority for the government. Inefficient use of energy, as evidenced from the results, affects output and the environment. It also impedes Egypt's achievement of sustainable development goals, especially SDG goals seven and twelve of 'affordable and clean energy', and 'responsible consumption and production', respectively.

\section{References}

Al-Ayouty, I., Hassaballa, H., El Hini, M. (2019). Carbon dioxide emissions: A spatial analysis of energy intensive industries in Egypt. In Proceedings of the 12 $2^{\text {th }}$ International Conference on Sustainable Energy and Environmental Protection, toward 100\% renewables, SEEP2019, Sharjah, United Arab Emirates; November 2019; A. Olabi, A. Alami, M. Tawalbeh, A. Inayat, Eds.; University of Sharjah: Sharjah, UAE, 438-446.

Brendt, E. R. (1980). Energy price increases and the productivity slowdown in United States manufacturing: The Decline in Productivity Growth. Federal Reserve Bank of Boston Conference Series. In Energy and economic growth in the USA: A multivariate approach; Stern, D. (1993), Energy Economic, 15, 137 150. 
Burgess, D. (1984). Energy prices, capital formation, and potential GNP, Energy Journal, 5(2), 1-26. In Energy and economic growth in the USA: A multivariate approach; Stern, D. (1993), Energy Economic, 15, $137-150$.

Castel, V. (2012). Reforming Energy Subsides in Egypt. Abidjan: African Development Bank.

Cleveland, C. J. (1995). Resource degradation, technical change, and the productivity of energy use in US agriculture, Ecological Economics, 13, 185-201. In A regression analysis of the effect of energy use in agriculture, Karkacier et al. (2005), Energy Policy, 34, 3976-3800.

Cleveland, C. J., Costanza, R., Hall, C.A.S., Kaufmann, R.K. (1984). Energy and the US economy: a biophysical perspective, Science, 225:890-897. In Energy and economic growth in the USA: A multivariate approach; Stern, D. (1993), Energy Economic, 15, 137-150.

Denison, E. (1979). Explanations of declining productivity growth, Brookings Institute General Series 354:1-24. . In Energy and economic growth in the USA: A multivariate approach; Stern, D. (1993), Energy Economic, 15, 137-150.

Felloni, F., Wahl I. T., Wandschneider, P. (1999). Evidence of the effect of infrastructure on agricultural production and productivity: Implications for China. In Chinese Agriculture and the WTO, Proceedings of the WCC-101, P. Wandschneider, (1999). bttps:// wmw.researchgate.net/publication/255606075 EVIDENCE OF THE EFFECT OF INFRA STRUCTURE ON AGRICULTURAL PRODUCTION AND PRODUCTIVITY IMPLICAT IONS FOR CHINA (accessed on 23, July, 2019)

Jorgenson, D.W. (1984). The role of energy in productivity growth. The American Economic Review, 74(2):26-30.

Kamel, B. (2017). A framework to promote energy efficiency as a solution to the energy problem in Egypt. Energy and Power Engineering, 9(3), 187-215.

Karkacier, O., Gokotolga, Z., Cicek, G. (2005). A regression analysis of the effect of energy use in agriculture. Energy Policy, 34, 3796-3800.

Mani, M., Wheeler, D. (1998). In search of pollution havens? Journal of Environment and Development, 7(3):215247.

Moghdassi, R., Pour, A. (2016). Energy consumption and total factor productivity growth in Iranian agriculture. Energy Reports, 2, 218-220.

Rasche R., Tatom, J. (1977). Energy resources and potential GNP, Federal Reserve Bank of St. Louis Review, 59(6), 10-24. In Energy and economic growth in the USA: A multivariate approach; Stern, D. (1993), Energy Economic, 15, 137-150.

Schurr, S. D. (1993). Energy and economic growth in the USA: A multivariate approach, Energy Economics, 15, 137-150.

Schurr, S. D. (1982). Energy efficiency and productive efficiency: Some thoughts based on American experience, The Energy Journal, 3(3), 3-14.

Stern, D. (1993). Energy and economic growth in the USA: A multivariate approach, Energy Economics, 15, 137150.

World Bank (2010). Egypt: Improve Energy Efficiency, World Bank Policy Note, The World Bank Open Repository https://openknowledge.worldbank.org/handle/10986/19466 (accessed on 23 July, 2019). 


\section{Appendix A: Summary of production function estimation and testing steps}

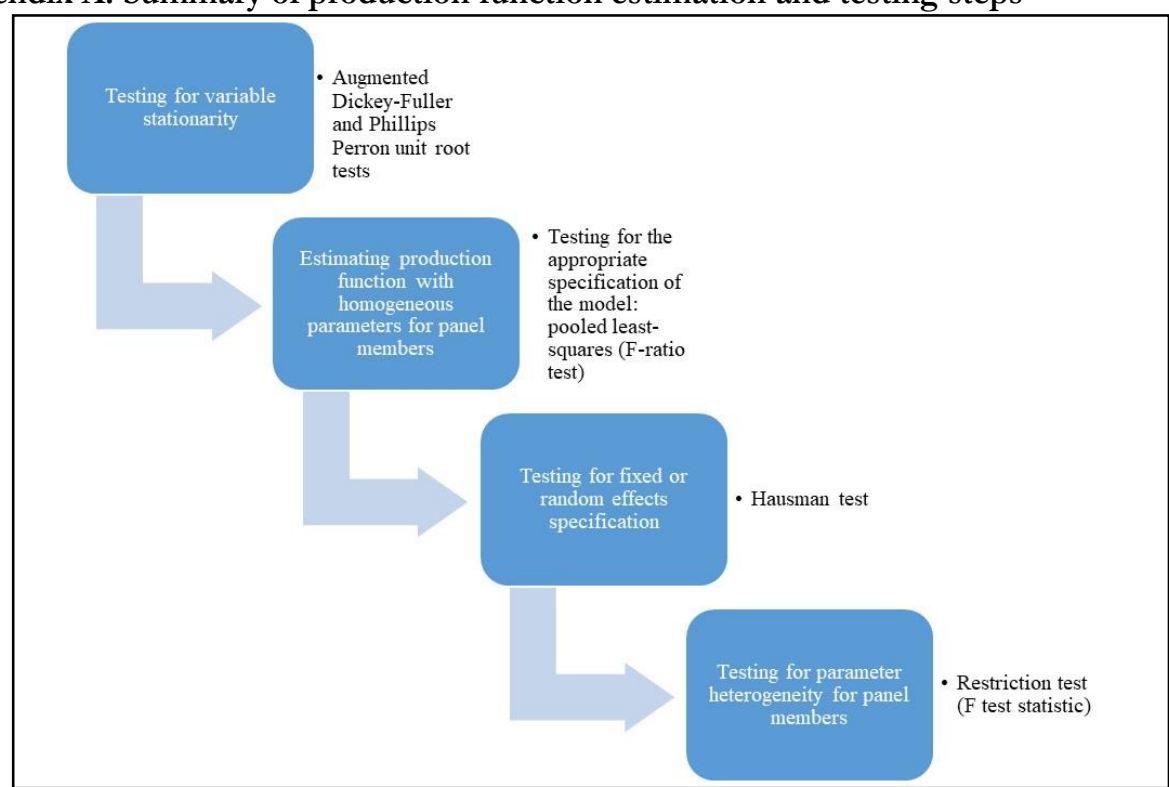

Source: Author's Computations 